\title{
Impactos socioeconômicos e ambientais do transporte ao processamento da cana-de-açúcar na Região Norte de Goiás
}

Submissão: 29/07/2021

Aceite: $19 / 09 / 2021$

\section{Resumo}

Gabriela Nobre Cunha'

Antonio Pasqualetto ${ }^{2}$

A cana-de-açúcar é uma cultura importante no Brasil, contudo, traz consigo inúmeras contestações devido os impactos associados. O objetivo deste estudo é o de analisar os impactos socioeconômicos e ambientais da agroindústria canavieira na região Norte de Goiás. A metodologia consistiu em utilizar a ferramenta de avaliação de impactos, seguindo as definições da resolução 01/86 do CONAMA e orientações da norma ISO 14001. Os resultados demonstraram que a agroindústria canavieira na região Norte do estado trouxe aumento na geração de vagas de emprego. Carece, contudo, de melhoria nas condições de trabalho e à saúde, bem como desenvolver estratégias de oportunidades à mão-de-obra durante o período de ociosidade das atividades agroindustriais.

Palavras-chave: Cana-de-açúcar. Cerrado. Agroindústria.

\section{Socioeconomic and environmental impacts of transportation to sugarcane processing in the Northern Goiás Region}

\begin{abstract}
Sugarcane is an important crop in Brazil however, it brings with it numerous challenges due to the associated impacts. The objective of this study is to analyze the socioeconomic and environmental impacts of the sugarcane agroindustry in the North of Goiás. The methodology consisted of using the impact assessment tool, following the definitions of CONAMA resolution 01/86 and ISO 14001 standard guidelines The results showed that the sugarcane agroindustry in the northern region of the state brought an increase in the generation of job vacancies. However, it lacks improvement in working conditions and health, as well as developing strategies to provide opportunities for the workforce during the idle period of agribusiness activities.
\end{abstract}

Keywords: Sugarcane. Cerrado. Agroindustry.

\section{Introdução}

A presença da cana-de-açúcar está condicionada a certos fatores da paisagem, bem como à existência de infraestrutura. Com relação ao estado de Goiás, por exemplo, 95\% de toda a área plantada com cana-de-açúcar situa-se até $30 \mathrm{~km}$ das usinas de álcool e açúcar, o que favorece a redução dos custos; por outro lado, gera a preocupação com os impactos ambientais e socioeconômicos que podem ocorrer na região, em função de a concentração das atividades do cultivo do produto (adubação, controle químico, entre outros) estar basicamente ao redor das usinas (RIBEIRO; FERREIRA; FERREIRA, 2010).

\footnotetext{
${ }^{1}$ Mestrado em Desenvolvimento e Planejamento Territorial (PUC-Goiás). https://orcid.org/0000-0002-9253-8339 E-mail: gabriela-nc@hotmail.com

2 Doutor em Fitotecnia (UFV). Professor e Coordenador do Programa de Pós-Graduação em Desenvolvimento e Planejamento Territorial da Pontifícia Universidade Católica de Goiás (PUC-GO). http://orcid.org/0000-0002-8639$\underline{6725}$ E-mail: profpasqualetto@gmail.com
} 
Não há como produzir biocombustíveis sem matéria-prima. A expansão do setor sucroalcooleiro é irreversível. Neste sentido, é necessário considerar os impactos positivos, como redução de gases do efeito estufa, menor dependência do petróleo, aumento da renda dos pequenos produtores, bem como seus efeitos negativos, como ambientais, agrícolas, agrários e socioeconômico (RIBEIRO, 2008).

A agroindústria canavieira vem provocando várias mudanças na dinâmica agrícola das regiões, gerando impactos na realidade socioeconômica dos estados e municípios produtores. (GILIO, 2015). Dessa forma, é essencial que os impactos socioeconômicos e ambientais do setor sejam abordados frente à potencialidade de expansão da cana-de-açúcar no Norte de Goiás (REZENDE; MAGALHÃES, 2012). Por isso, este trabalho teve como objetivo analisar os impactos socioeconômicos e ambientais da agroindústria canavieira no Norte de Goiás.

\section{Metodologia}

A área alvo da investigação é a mesorregião norte de Goiás, nas microrregiões de Porangatu e Chapada dos Veadeiros, sendo o estudo desenvolvido para o ano de 2020. Procedeuse à avaliação dos aspectos e dos impactos ambientais (SANCHEZ, 2020) relacionados ao setor industrial, envolvendo desde o transporte até o processamento da cana-de-açúcar. Assim, os impactos ambientais destas atividades sucroalcooleiras foram analisados e classificados de acordo com a Norma ISO 14001 (ASSOCIAÇÃO BRASILEIRA DE NORMAS TÉCNICAS - ABNT, 2015) e adaptados de acordo com Silva, Shibao e Santos (2015) (Quadro 1).

À luz dos atributos definidos no quadro 1, na próxima página, as atividades impactantes, os aspectos ambientais, as medidas ambientais e o setor responsável pela execução foram identificados e expressos em quadros demonstrativos em cada etapa da parte industrial, do transporte ao processamento da cana-de-açúcar.

\section{Resultados e Discussão}

O meio ambiente pode ser definido, segundo o inciso XII do Conselho Nacional do Meio Ambiente (CONAMA) de 2002, como o "[...] conjunto de condições, leis, influência e interações de ordem física, química, biológica, social, cultural e urbanística, que permite, abriga e rege a vida em todas as suas formas" (BRASIL, 2002). 
Quadro 1 - Atributos utilizados para classificar os impactos ambientais

\begin{tabular}{|c|c|c|c|}
\hline ANÁLISE & \multicolumn{2}{|c|}{ CLASSIFICAÇÃO } & DESCRIÇÃO \\
\hline \multirow{3}{*}{$\begin{array}{l}\text { Fator do } \\
\text { ambiente }\end{array}$} & \multicolumn{2}{|r|}{ Antrópico } & $\begin{array}{l}\text { Tudo aquilo que resulta da ação humana; tudo o que foi } \\
\text { modificado pelo ser humano. É conhecido também como meio } \\
\text { socioeconômico. }\end{array}$ \\
\hline & \multicolumn{2}{|r|}{ Físico } & $\begin{array}{l}\text { É o espaço que acomoda todos os outros meios. Ele os sustenta e } \\
\text { dá condições para que haja o desenvolvimento de todos os outros } \\
\text { meios. Em resumo: solo, água e ar. }\end{array}$ \\
\hline & \multicolumn{2}{|r|}{ Biótico } & Refere-se a tudo que tem vida. Exemplo: flora e fauna. \\
\hline \multirow{3}{*}{ Temporalidade } & AT & Atual & $\begin{array}{l}\text { Atividades, processos, produtos e serviços realizados no presente } \\
\text { ou consequências do presente. }\end{array}$ \\
\hline & PA & Passado & Atividades, processos, produtos e serviços obsoletos. \\
\hline & FU & Futuro & $\begin{array}{l}\text { Atividades, processos, produtos e serviços em fase de } \\
\text { planejamento ou consequências futuras. }\end{array}$ \\
\hline \multirow{2}{*}{ Influência } & $\mathrm{D}$ & Direta & Capacidade de controle do aspecto ambiental. \\
\hline & I & Indireta & Capacidade de intervenção no controle do aspecto ambiental. \\
\hline \multirow{3}{*}{ Situação } & $\mathrm{N}$ & Normal & Condição padrão de trabalho. \\
\hline & AN & Anormal & $\begin{array}{l}\text { Condição extraordinária de trabalho (abaixo/acima da capacidade } \\
\text { de operação). }\end{array}$ \\
\hline & $\mathrm{E}$ & Emergencial & Condição potencial para a ocorrência de impacto ambiental. \\
\hline \multirow[b]{2}{*}{ Tipo } & + & Positivo & Resulta em melhorias para o ambiente. \\
\hline & - & Negativo & $\begin{array}{l}\text { Alterações que causam algum risco para o ser humano ou para os } \\
\text { recursos naturais encontrados no espaço. }\end{array}$ \\
\hline \multirow{4}{*}{$\begin{array}{l}\text { Órgão } \\
\text { executor }\end{array}$} & AA & Agroindústria & Atividade econômica da industrialização do produto agrícola. \\
\hline & SE & $\begin{array}{c}\text { Setor } \\
\text { Empresarial }\end{array}$ & $\begin{array}{l}\text { Setor de organização econômica, civil ou comercial, constituída } \\
\text { para explorar um ramo de negócio e oferecer ao mercado bens } \\
\text { e/ou serviços. }\end{array}$ \\
\hline & OP & $\begin{array}{l}\text { Órgãos de } \\
\text { Pesquisa }\end{array}$ & $\begin{array}{l}\text { Órgão responsável por um conjunto de atividades que tem por } \\
\text { finalidade descobrir novos conhecimentos nos domínios científico, } \\
\text { literário, artístico etc. }\end{array}$ \\
\hline & SG & $\begin{array}{c}\text { Setor } \\
\text { Governamental }\end{array}$ & $\begin{array}{l}\text { Setor de instância máxima da administração executiva, } \\
\text { geralmente reconhecida como a liderança de uma Nação. }\end{array}$ \\
\hline
\end{tabular}

Fonte: Adaptado de ABNT (2015) e Silva, Shibao e Santos (2015).

As atividades desenvolvidas no meio ambiente geram aspectos que podem levar ao impacto ambiental. Assim, a NBR ISO 14001/2015 define aspecto ambiental como o "elemento das atividades ou produtos ou serviços de uma organização que pode interagir com o meio ambiente"; por sua vez, impacto ambiental é definido como "qualquer modificação do meio ambiente, adversa ou benéfica, que resulte, no todo ou em parte, dos aspectos ambientais da organização" (ABNT, 2015, n. p.).

A Resolução CONAMA n.ำ 01, de 1986, em seu Art. 1으, define impacto ambiental da seguinte forma: 
Art. 1 [...] qualquer alteração das propriedades físicas, químicas e biológicas do meio ambiente, causada por qualquer forma de matéria ou energia resultante das atividades humanas que, direta ou indiretamente, afetam:

I - a saúde, a segurança e o bem-estar da população;

II - as atividades sociais e econômicas;

III - a biota;

IV - as condições estéticas e sanitárias do meio ambiente;

$\mathrm{V}$ - a qualidade dos recursos ambientais. (BRASIL, 1986)

Os impactos podem ser classificados em positivos e negativos, e são definidos, de acordo com Silva (2004, p. 72), como: impactos positivos ou benéficos, "quando a ação resulta na melhoria da qualidade de um fator ou parâmetro ambiental; os impactos ambientais positivos devem ser estimulados pelas autoridades governamentais"; e impactos negativos ou adversos, "quando a ação resulta em um dano à qualidade de um fator ou parâmetro ambiental; os impactos ambientais negativos devem ser evitados pela população de um modo geral e reprimidos pelas autoridades ambientais". Os principais impactos relacionados à evacuação da cana-de-açúcar para a usina sucroalcooleira estão dispostos no quadro 1.

Dentre os impactos negativos: a queima de combustíveis e trânsito de máquinas, implementos e veículos na lavoura; a concentração de particulados pela intensa mobilização de veículos; o uso de máquinas e equipamentos para o carregamento e o transporte da cana; e o maior tráfego de veículos longos e pesados durante o transporte da cana para beneficiamento.

Miranda (2013) afirma que materiais particulados resultantes da queima de combustíveis fósseis podem causar sérios problemas, como a ocorrência de doenças respiratórias e cardíacas, com possível chances de comprometer a vida humana. O autor afirma ainda que certos particulados "atuam como carreadores de bactérias, vírus, produtos químicos tóxicos e poluem a água, o solo, plantas e alimentos, além do ar" (MIRANDA, 2013, p. 1).

Outro problema comum é a poeira causada pelo tráfego dos veículos para escoamento dos colmos da cana do canavial até a agroindústria. Esses problemas podem ser reduzidos com o molhamento das vias. Todavia, outro impacto pode ocorrer: a pressão sobre os recursos hídricos. Muitas usinas utilizam a própria vinhaça para realizar esse molhamento. Quando utilizada de maneira adequada, configura-se em solução viável.

Por fim, relacionada ao setor produtivo, uma das maiores preocupações diz respeito aos impactos aos recursos hídricos promovidos pelo cultivo da cana-de-açúcar, advindos do uso excessivo de adubos, corretivos e fertilizantes, o que pode contaminar as águas de superfície do solo. Ressalta-se que o uso da vinhaça e de efluentes líquidos aplicados à cultura - quando empregados de forma correta - tende a minimizar os prejuízos aos sistemas hídricos; por outro lado, quando se faz uso inadequado, pode potencializar os danos ambientais (PASSOS, 2015). 
Quadro 1 - Listagem descritiva de aspectos, impactos ambientais e suas devidas classificações na atividade de transporte dos colmos de cana-de-açúcar para beneficiamento

\begin{tabular}{|c|c|c|c|c|c|c|c|c|c|c|}
\hline \multicolumn{11}{|c|}{ ATIVIDADE IMPACTANTE: transporte de colmos da cana-de-açúcar para usina sucroalcooleira } \\
\hline \multicolumn{11}{|c|}{ ASPECTO AMBIENTAL: processo de deslocamento dos colmos da colheita até usina } \\
\hline \multirow[b]{2}{*}{$\begin{array}{c}\text { IMPACTO } \\
\text { AMBIENTAL }\end{array}$} & \multirow{2}{*}{ 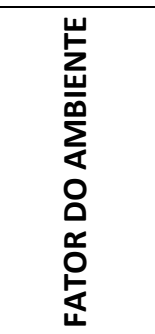 } & \multirow{2}{*}{ 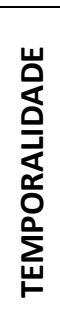 } & \multirow{2}{*}{ 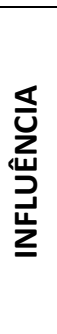 } & \multirow{2}{*}{ 足 } & \multirow[b]{2}{*}{ 을 } & \multirow[b]{2}{*}{ MEDIDA AMBIENTAL } & \multicolumn{4}{|c|}{$\begin{array}{c}\text { EXECUTOR } \\
\text { RESPONSÁVEL }\end{array}$} \\
\hline & & & & & & & AA & SE & $\mathrm{OP}$ & SG \\
\hline $\begin{array}{lr}\begin{array}{l}\text { 1. Queima de } \\
\text { combustíveis }\end{array} \\
\text { trânsito } \\
\text { máquinas, } \\
\text { implementos } \\
\text { veículos na lavoura. }\end{array}$ & físico & AT & $\mathrm{D}$ & $\mathrm{N}$ & - & \multirow{2}{*}{$\begin{array}{l}\text { - Utilizar caminhões- } \\
\text { pipas para irrigar as } \\
\text { estradas e carreadores } \\
\text { com intenso tráfego de } \\
\text { veículos. }\end{array}$} & \multirow[t]{2}{*}{$x$} & & & \\
\hline $\begin{array}{l}\text { 2. Concentração de } \\
\text { particulados pela } \\
\text { intensa mobilização } \\
\text { de veículos. }\end{array}$ & físico & AT & I & $\mathrm{N}$ & - & & & & & \\
\hline $\begin{array}{l}\text { 3. Maior uso de } \\
\text { máquinas } \\
\text { equipamentos para } \\
\text { o carregamento e } \\
\text { transporte da cana. }\end{array}$ & antrópico & AT & $\mathrm{D}$ & $\mathrm{N}$ & - & $\begin{array}{l}\text { - Estabelecer maior } \\
\text { espaçamento entre } \\
\text { linhas em intervalos } \\
\text { regulares dentro da } \\
\text { lavoura que permitam } \\
\text { a movimentação de } \\
\text { caminhões apenas } \\
\text { nesses locais pré- } \\
\text { determinados. }\end{array}$ & $x$ & & & \\
\hline $\begin{array}{l}\text { 4. Maior tráfego de } \\
\text { veículos longos e } \\
\text { pesados durante o } \\
\text { transporte da cana } \\
\text { para } \\
\text { beneficiamento. }\end{array}$ & antrópico & AT & $D$ & $\mathrm{~N}$ & - & $\begin{array}{l}\text { - Melhorar a } \\
\text { sinalização nos trechos } \\
\text { de rodovia onde o } \\
\text { tráfego de caminhões } \\
\text { transportadores de } \\
\text { cana-de-açúcar é mais } \\
\text { intenso; } \\
\text { - Aumentar a } \\
\text { fiscalização rodoviária } \\
\text { nesses mesmos } \\
\text { trechos. }\end{array}$ & & & & $x$ \\
\hline
\end{tabular}

Obs.: AT: atual; PA: passado; FU: futuro; D: direta; I: indireta; N: normal; AN: anormal; E: emergencial; (+): positivo; (-): negativo; AA: agroindústria; SE: setor empresarial; OP: órgãos de pesquisa; SG: setor governamental. Fonte: Elaborado pelos autores (2021).

Para minimizar o efeito desses impactos, é importante utilizar caminhões-pipas para irrigar as estradas e os carreadores com intenso tráfego de veículos; estabelecer maior espaçamento entre linhas em intervalos regulares dentro da lavoura que permitam a movimentação de caminhões apenas nesses locais pré-determinados; melhorar a sinalização nos trechos de rodovia onde o tráfego de caminhões transportadores de cana-de-açúcar é mais intenso; e aumentar a fiscalização rodoviária nesses mesmos trechos. 
De forma geral, o setor sucroalcooleiro é altamente dependente de recursos naturais, principalmente água e solo. Quando essa indústria se instala em regiões como o Norte Goiano, com solos mais pobres e menor disponibilidade de recursos hídricos, a agroindústria tende a utilizar quantidade de resíduos líquidos como fertilizantes, a fim de reduzir os gastos com insumos. Todavia, isso pode causar prejuízos ambientais adversos na região, além de provocar impactos econômicos e sociais importantes (PIACENTE, 2005; ALVARENGA \& QUEIROZ, 2012; SOUZA et al., 2015).

A cultura da cana-de-açúcar e a atividade industrial, gera impactos no meio ambiente, à medida que emprega recursos naturais, como água e solo, e faz uso de resíduos líquidos, insumos e defensivos químicos, como vinhaça, fertilizantes e pesticidas (RODRIGUES, 2010). Nota-se que o setor sucroalcooleiro da região Norte de Goiás necessita de produção mais limpa, bem como produtos e serviços que possam mitigar os impactos negativos sobre o meio ambiente. Além disso, é mister uma abordagem de proteção ambiental ampla, que considera todas as fases do processo de manufatura, com os objetivos de prevenir e minimizar o risco para os seres humanos e o ambiente a curto e longo prazo. Essa abordagem requer ações para minimizar o consumo de energia e matéria-prima e a geração de resíduos e emissões (BARBIERI, 2007; LEONARDO et al., 2012).

Ressalta-se que a indústria canavieira ainda é alvo de muitas críticas, devido aos impactos ambientais negativos. É válido destacar, contudo, que, ao aderir às iniciativas ambientais, o setor sucroalcooleiro pode obter lucratividade em vários segmentos. Dessa forma, o que é visto como problema pode se transformar em oportunidade, pois a aplicação de resíduos na fertirrigação, na adubação e como biomassa pode tornar a atividade mais sustentável, sem tantas implicações no meio ambiente e na saúde humana (PAIVA \& MARIA, 2018).

Considerando apenas a fase industrial do setor sucroalcooleiro, os principais impactos são: a geração de resíduos, como a vinhaça e a torta de filtro; a utilização intensiva de água e o forte odor gerado na fase de fermentação; e a destilação para a produção de álcool (NOGUEIRA \& GARCIA, 2013). Toda atividade gera resíduos ou perdas e, quando o reaproveitamento desses resíduos não é realizado de maneira correta ou tratados adequadamente, esse material entra em contato com o meio ambiente, provocando impactos, na maioria das vezes, devastadores (PACHECO \& SILVA, 2008; CRUZ et al., 2016).

Quando se tem a alta temporada no processo de produção de açúcar e álcool, o setor da agroindústria necessita, assim como o setor agrícola, contratar mão-de-obra sazonal (Quadro 2). 
Quadro 2 - Listagem descritiva de aspectos, impactos ambientais e suas devidas classificações na atividade de contratação de mão-de-obra sazonal no processo produtivo de açúcar e álcool.

\begin{tabular}{|c|c|c|c|c|c|c|c|c|c|c|}
\hline \multicolumn{11}{|c|}{ ATIVIDADE IMPACTANTE: contratação de mão-de-obra sazonal } \\
\hline \multicolumn{11}{|c|}{ ASPECTO AMBIENTAL: processo de utilização de mão-de-obra na agroindústria da cana-de-açúcar } \\
\hline \multirow[b]{2}{*}{$\begin{array}{c}\text { IMPACTO } \\
\text { AMBIENTAL }\end{array}$} & \multirow{2}{*}{ 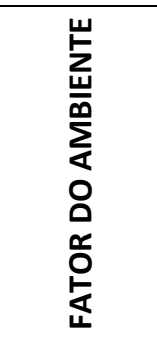 } & \multirow{2}{*}{ 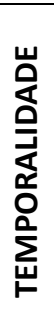 } & \multirow{2}{*}{ 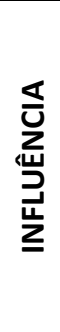 } & \multirow{2}{*}{ 원 } & \multirow[b]{2}{*}{ 을 } & \multirow[b]{2}{*}{ MEDIDA AMBIENTAL } & \multicolumn{4}{|c|}{$\begin{array}{c}\text { EXECUTOR } \\
\text { RESPONSÁVEL }\end{array}$} \\
\hline & & & & & & & $\mathrm{AA}$ & SE & $\mathrm{OP}$ & SG \\
\hline $\begin{array}{l}\text { 1. Expansão da } \\
\text { atividade } \\
\text { agroindustrial. }\end{array}$ & antrópico & FU & I & $\mathrm{N}$ & + & $\begin{array}{l}\text { - Executar programas de } \\
\text { exploração de culturas } \\
\text { intercalares ou em } \\
\text { sucessão para aproveitar a } \\
\text { mão-de-obra ociosa } \\
\text { durante a entressafra da } \\
\text { cana. }\end{array}$ & $x$ & & & \\
\hline $\begin{array}{l}\text { 2. Necessidade } \\
\text { de contingente } \\
\text { de mão-de-obra } \\
\text { na etapa de } \\
\text { fabricação e } \\
\text { açúcar e álcool. }\end{array}$ & antrópico & $\mathrm{FU}$ & $\mathrm{D}$ & $\mathrm{N}$ & + & $\begin{array}{l}\text { - Estabelecer turnos de } \\
\text { trabalho, aumentando a } \\
\text { oferta de empregos. }\end{array}$ & $x$ & & & \\
\hline $\begin{array}{l}\text { 3. Remuneração } \\
\text { e distribuição da } \\
\text { riqueza entre o } \\
\text { campo e a } \\
\text { cidade. }\end{array}$ & antrópico & FU & $\mathrm{D}$ & $\mathrm{N}$ & + & $\begin{array}{l}\text { - Incentivar a criação de } \\
\text { opções de lazer e de } \\
\text { compras na região, } \\
\text { permitindo a não evasão } \\
\text { de recursos para outros } \\
\text { centros. }\end{array}$ & & $x$ & & \\
\hline $\begin{array}{l}\text { 4. Força de } \\
\text { trabalho local. }\end{array}$ & antrópico & AT & $\mathrm{D}$ & $\mathrm{N}$ & + & $\begin{array}{l}\text { - Dar preferência de } \\
\text { emprego à população das } \\
\text { proximidades da cultura da } \\
\text { cana-de-açúcar. }\end{array}$ & $x$ & & & \\
\hline
\end{tabular}

Obs.: A: adversa; B: benéfica; AT: atual; PA: passado; FU: futuro; D: direta; I: indireta; N: normal; AN: anormal; E: emergencial; (+): positivo; (-): negativo; AA: agroindústria; SE: setor empresarial; OP: órgãos de pesquisa; SG: setor governamental.

Fonte: Elaborado pelos autores (2021).

Essa atividade gera impactos positivos, como: expansão da atividade agroindustrial; necessidade de contingente de mão-de-obra na etapa de fabricação de açúcar e álcool; remuneração e distribuição da riqueza entre o campo e a cidade; e força de trabalho local. Neste sentido, salienta-se que as empresas devem cumprir a responsabilidade social. Dessa forma, devem estabelecer ações que promovam o bem-estar de sua população interna e externa (CARVALHO, VIAN, BRAUN, 2011).

Ao avaliarem a mecanização agropecuária e o mercado de trabalho formal no cultivo da cana-de-açúcar no Nordeste, Silva Filho, Silva e Lima (2014) demonstraram aumento nos postos de trabalho no setor; porém, verificaram alta rotatividade dos trabalhadores, o que mostra 
atividade sazonal para o mercado de trabalho regional, com baixos salários e poucos anos de estudo da mão-de-obra. Para maximizar o efeito dos impactos negativos, algumas medidas são necessárias: executar programas de exploração de culturas intercalares ou em sucessão, para aproveitar a mão-de-obra ociosa durante a entressafra da cana; estabelecer turnos de trabalho, aumentando a oferta de empregos; incentivar a criação de opções de lazer e de compras na região, permitindo a não evasão de recursos para outros centros; e dar preferência de emprego à população das proximidades da cultura da cana-de-açúcar. Carvalho (2007) e Carvalho et al. (2011) abordam este tema.

A atividade de tratamento inicial da cana-de-açúcar, na chegada à indústria, provoca vários impactos ambientais negativos, como: pressão hídrica pelo consumo de água no sistema produtivo de uma usina sucroalcooleira; geração de efluentes, devido à limpeza dos gomos da cana-de-açúcar, podendo causar contaminações no solo e na água; geração de resíduos sólidos provindos da limpeza da cana-de-açúcar, podendo causar danos ao meio ambiente; e poluição sonora (Quadro 3).

Metcalf e Eddy (2016) demonstraram a importância do tratamento e do reuso dos efluentes industriais. Com o tratamento, a água contaminada não é depositada in natura nos corpos hídricos; consequentemente, deixa de causar sérias poluições nesse meio. 0 reuso na própria indústria torna-se alternativa mais barata, pois o recurso potável é oneroso para o uso industrial; o reuso também favorece maior conservação dos mananciais hídricos, haja vista que reduz a captação de água.

Outro problema comum nesse ambiente é a poluição sonora. Dias, Macêdo e Pelli (2018) relatam que esse impacto pode causar vários distúrbios aos seres humanos, como perda da audição, zumbido, alteração no sono, estresse, perda do desempenho cognitivo, depressão, irritação e vários outros distúrbios. Além disso, esses mesmos autores afirmam que trabalhadores estressados podem desenvolver doenças mais graves, como hipertensão e doenças cardiovasculares.

Para amenizar esses impactos negativos, deve-se: realizar estudos, viabilizando e otimizando, ao máximo, o consumo hídrico; realizar o devido tratamento e o reuso de água no processo; realizar a gestão dos resíduos, reaproveitando-os no processo industrial; seguir as normas e utilizar o equipamento de proteção individual; e utilizar equipamentos e promover métodos que minimizem os efeitos sonoros. 
Quadro 3 - Listagem descritiva de aspectos, impactos ambientais e suas devidas classificações na atividade de tratamento inicial da cana-de-açúcar na chegada à indústria.

\begin{tabular}{|c|c|c|c|c|c|c|c|c|c|c|}
\hline \multicolumn{11}{|c|}{ ATIVIDADE IMPACTANTE: tratamento inicial da cana-de-açúcar na indústria } \\
\hline \multicolumn{11}{|c|}{ ASPECTO AMBIENTAL: processos de recepção, limpeza e preparo da cana-de-açúcar } \\
\hline \multirow[b]{2}{*}{$\begin{array}{c}\text { IMPACTO } \\
\text { AMBIENTAL }\end{array}$} & \multirow{2}{*}{ 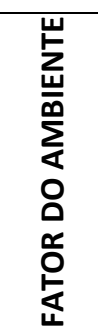 } & \multirow{2}{*}{ 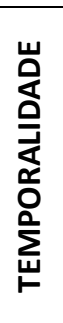 } & \multirow{2}{*}{ 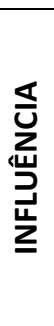 } & \multirow{2}{*}{ 迹 } & \multirow[b]{2}{*}{ 율 } & \multirow[b]{2}{*}{ MEDIDA AMBIENTAL } & \multicolumn{4}{|c|}{$\begin{array}{c}\text { EXECUTOR } \\
\text { RESPONSÁVEL }\end{array}$} \\
\hline & & & & & & & $\mathrm{AA}$ & SE & OP & SG \\
\hline $\begin{array}{l}\text { 1. Aumento da } \\
\text { pressão hídrica pelo } \\
\text { consumo de água no } \\
\text { sistema produtivo de } \\
\text { uma usina } \\
\text { sucroalcooleira. }\end{array}$ & físico & AT & I & $\mathrm{N}$ & - & $\begin{array}{l}\text { - Realizar estudos, } \\
\text { viabilizando } \\
\text { otimizando, ao máximo, } \\
\text { o consumo hídrico. }\end{array}$ & $X$ & & $\mathrm{X}$ & \\
\hline $\begin{array}{l}\text { 2. Maior geração de } \\
\text { efluentes, advindos } \\
\text { da limpeza dos gomos } \\
\text { da cana-de-açúcar, } \\
\text { podendo causar } \\
\text { contaminações no } \\
\text { solo e na água. }\end{array}$ & físico & AT & $\mathrm{D}$ & $\mathrm{N}$ & - & $\begin{array}{l}\text { - Realizar o devido } \\
\text { tratamento e o reuso de } \\
\text { água no processo. }\end{array}$ & $X$ & & & \\
\hline $\begin{array}{l}\text { 3. Maior geração de } \\
\text { resíduos sólidos } \\
\text { provindos da limpeza } \\
\text { da cana-de-açúcar, } \\
\text { podendo causar } \\
\text { danos ao meio } \\
\text { ambiente. }\end{array}$ & físico & AT & $\mathrm{D}$ & $\mathrm{N}$ & - & $\begin{array}{l}\text { - Realizar a gestão dos } \\
\text { resíduos, } \\
\text { reaproveitando-os no } \\
\text { processo industrial. }\end{array}$ & $x$ & & & \\
\hline 4. Poluição sonora. & físico & AT & $\mathrm{D}$ & $\mathrm{N}$ & - & $\begin{array}{l}\text { - Seguir as normas e } \\
\text { utilizar o equipamento } \\
\text { de proteção individual; } \\
\text { - Utilizar equipamentos e } \\
\text { promover métodos que } \\
\text { minimizem os efeitos } \\
\text { sonoros. }\end{array}$ & $X$ & & $x$ & \\
\hline
\end{tabular}

Obs.: A: adversa; B: benéfica; AT: atual; PA: passado; FU: futuro; D: direta; I: indireta; N: normal; AN: anormal; E: emergencial; (+): positivo; (-): negativo; AA: agroindústria; SE: setor empresarial; OP: órgãos de pesquisa; SG: setor governamental.

Fonte: Elaborado pelos autores (2021).

Depois de limpos, os colmos da cana-de-açúcar seguem para o processo de extração do caldo, através do processo de moagem. Essa atividade causa impactos negativos, como geração de efluentes, provenientes do processo de limpeza do sistema de extração do caldo, podendo provocar degradações ao meio ambiente e poluição sonora (Quadro 4).

Como citado anteriormente, Metcalf e Eddy (2016) descrevem a importância do tratamento e do reuso dos efluentes industriais. Esse tratamento pode resultar em economia para a empresa, assim como conservar os mananciais de água. 
Quadro 4 - Listagem descritiva de aspectos, impactos ambientais e suas devidas classificações na atividade de moagem da cana-de-açúcar

\begin{tabular}{|c|c|c|c|c|c|c|c|c|c|c|}
\hline \multicolumn{11}{|c|}{ ATIVIDADE IMPACTANTE: moagem da cana-de-açúcar } \\
\hline \multicolumn{11}{|c|}{ ASPECTO AMBIENTAL: processo de extração do caldo da cana-de-açúcar } \\
\hline \multirow[b]{2}{*}{ IMPACTO AMBIENTAL } & \multirow{2}{*}{ 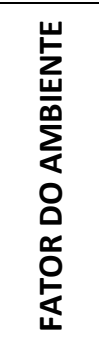 } & \multirow{2}{*}{ 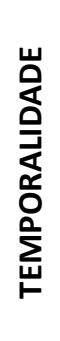 } & \multirow{2}{*}{ 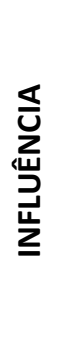 } & \multirow{2}{*}{ 选 } & \multirow[b]{2}{*}{ 을 } & \multirow[b]{2}{*}{ MEDIDA AMBIENTAL } & \multicolumn{4}{|c|}{$\begin{array}{c}\text { EXECUTOR } \\
\text { RESPONSÁVEL }\end{array}$} \\
\hline & & & & & & & $\mathrm{AA}$ & SE & OP & SG \\
\hline $\begin{array}{l}\text { 1. Maior geração de } \\
\text { efluente, proveniente } \\
\text { do processo de limpeza } \\
\text { do sistema de extração } \\
\text { do caldo, podendo } \\
\text { causar degradações ao } \\
\text { meio ambiente. }\end{array}$ & físico & AT & $\mathrm{D}$ & $\mathrm{N}$ & - & $\begin{array}{l}\text { - Realizar o devido } \\
\text { tratamento e o reuso de } \\
\text { água no processo. }\end{array}$ & $x$ & & & \\
\hline $\begin{array}{l}\text { 2. Produção do bagaço } \\
\text { de cana-de-açúcar, } \\
\text { podendo degradar o } \\
\text { meio ambiente. }\end{array}$ & físico & AT & $\mathrm{D}$ & $\mathrm{N}$ & - & $\begin{array}{l}\text { - Realizar a gestão dos } \\
\text { resíduos, } \\
\text { reaproveitando-os na } \\
\text { cogeração de energia. }\end{array}$ & $\mathrm{X}$ & & & \\
\hline 3. Poluição sonora. & físico & AT & $D$ & $\mathrm{~N}$ & - & $\begin{array}{l}\text { - Seguir as normas e } \\
\text { utilizar equipamentos de } \\
\text { proteção individual; } \\
\text { - Utilizar equipamentos e } \\
\text { empregar métodos que } \\
\text { minimizem os efeitos } \\
\text { sonoros. }\end{array}$ & $x$ & & $x$ & \\
\hline
\end{tabular}

Obs.: A: adversa; B: benéfica; AT: atual; PA: passado; FU: futuro; D: direta; I: indireta; N: normal; AN: anormal; E: emergencial; (+): positivo; (-): negativo; AA: agroindústria; SE: setor empresarial; OP: órgãos de pesquisa; SG: setor governamental.

Fonte: Elaborado pelos autores (2021).

Outro impacto importante advindo dessa atividade é a geração do bagaço de cana-deaçúcar. Avaliando as formas de gestão e aplicação de resíduos da cana-de-açúcar, visando à redução de impactos ambientais, Schneider et al. (2012) demonstraram que o bagaço pode gerar impactos ambientais negativos, como pressão no solo e na água. Como impactos positivos, encontram-se: o subproduto é utilizado na geração energética na própria indústria; e o bagaço pode ser utilizado na alimentação animal.

Tendo em vista a mitigação desses impactos negativos, deve-se realizar o devido tratamento e o reuso de água no processo. Além deste, deve-se seguir as normas e utilizar equipamentos de proteção individual, utilizar equipamentos e promover métodos que minimizem os efeitos sonoros do processo e realizar a gestão dos resíduos, especialmente o bagaço, reaproveitando-os na cogeração de energia. 
Depois da extração do caldo da cana-de-açúcar, dois processos diferentes são estabelecidos: um voltado para a produção de açúcar, e outro, para a produção do álcool. No processo de produção de açúcar, são gerados impactos negativos, oriundos da geração de efluente, proveniente da limpeza do sistema de produção de açúcar; geração do melaço de canade-açúcar; geração da torta de filtro; e poluição sonora (Quadro 5).

Quadro 5 - Listagem descritiva de aspectos, impactos e suas devidas classificações na atividade de produção do açúcar.

\begin{tabular}{|c|c|c|c|c|c|c|c|c|c|c|}
\hline \multicolumn{11}{|c|}{ ATIVIDADE IMPACTANTE: produção do açúcar } \\
\hline \multicolumn{11}{|c|}{ ASPECTO AMBIENTAL: processos de formação do caldo, evaporação, cozimento, centrífuga e secagem } \\
\hline \multirow[b]{2}{*}{$\begin{array}{l}\text { IMPACTO } \\
\text { AMBIENTAL }\end{array}$} & \multirow{2}{*}{ 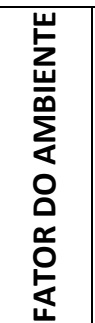 } & \multirow{2}{*}{ 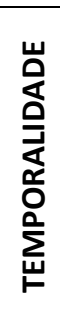 } & \multirow{2}{*}{ 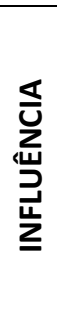 } & \multirow{2}{*}{ 迹 } & \multirow[b]{2}{*}{ 음 } & \multirow[b]{2}{*}{ MEDIDA AMBIENTAL } & \multicolumn{4}{|c|}{$\begin{array}{c}\text { EXECUTOR } \\
\text { RESPONSÁVEL }\end{array}$} \\
\hline & & & & & & & AA & SE & $\mathrm{OP}$ & SG \\
\hline $\begin{array}{l}\text { 1. Maior geração de } \\
\text { efluentes, devido à } \\
\text { limpeza do sistema } \\
\text { de produção de } \\
\text { açúcar. }\end{array}$ & físico & AT & $\mathrm{D}$ & $\mathrm{N}$ & - & $\begin{array}{l}\text { - Realizar o devido tratamento } \\
\text { e o reuso de água no processo. }\end{array}$ & $\mathrm{X}$ & & & \\
\hline $\begin{array}{l}\text { 2. Maior produção } \\
\text { do melaço de cana- } \\
\text { de-açúcar. }\end{array}$ & físico & AT & $\mathrm{D}$ & $\mathrm{N}$ & - & $\begin{array}{l}\text { - Utilizar melaço na agricultura, } \\
\text { pois aumenta a vida } \\
\text { microbiana, o que faz com que } \\
\text { as plantas absorvam mais } \\
\text { nutrientes; também funciona } \\
\text { como forma de controlar } \\
\text { biologicamente possíveis } \\
\text { pragas e como alimento para } \\
\text { bactérias saudáveis. }\end{array}$ & $\mathrm{X}$ & & $\mathrm{X}$ & \\
\hline $\begin{array}{l}\text { 3. Aumento de } \\
\text { resíduos da torta de } \\
\text { filtro. }\end{array}$ & físico & AT & $\mathrm{D}$ & $\mathrm{N}$ & - & $\begin{array}{l}\text { - Aproveitar resíduos da torta } \\
\text { de filtro na agricultura, visto } \\
\text { que é rica em fósforo, cálcio e } \\
\text { possui consideráveis } \\
\text { quantidades de } \\
\text { micronutrientes. Além disso, } \\
\text { sua umidade garante a brotação } \\
\text { da cana-de-açúcar em plantios } \\
\text { feitos em épocas de inverno na } \\
\text { região Centro-Sul. }\end{array}$ & $\mathrm{X}$ & & $\mathrm{X}$ & \\
\hline 4. Poluição sonora. & físico & AT & $\mathrm{D}$ & $\mathrm{N}$ & - & $\begin{array}{l}\text { - Seguir as normas e utilizar } \\
\text { equipamentos de proteção } \\
\text { individual; } \\
\text { - Utilizar equipamentos e } \\
\text { empregar métodos que } \\
\text { minimizem os efeitos sonoros. }\end{array}$ & $\mathrm{x}$ & & $\mathrm{X}$ & \\
\hline
\end{tabular}

Obs.: A: adversa; B: benéfica; AT: atual; PA: passado; FU: futuro; D: direta; I: indireta; N: normal; AN: anormal; E: emergencial; (+): positivo; (-): negativo; AA: agroindústria; SE: setor empresarial; OP: órgãos de pesquisa; SG: setor governamental.

Fonte: Elaborado pelos autores (2021). 
Marcelino et al. (2013) afirmam a importância do tratamento de efluentes, como destruição de contaminantes não biodegradáveis (corantes, agrotóxicos, fármacos, entre outros), remoção de metais pesados ( $\mathrm{Cr}$, $\mathrm{Pb}$ etc.), tratamento de efluentes oleosos, reaproveitamento de resíduos siderúrgicos, entre outros. Esses autores mostram a importância de tratamentos alternativos para as águas residuárias, visando à sua reutilização e à mitigação de impactos causados pelos seus lançamentos.

Outro impacto advindo dessa atividade é a geração da torta de filtro. Esse subproduto provém da mistura de bagaço moído e lodo da decantação da etapa de clarificação do açúcar (FRAVET et al., 2010). A torta de filtro, quando não bem manejada, pode causar efeitos danosos aos recursos hídricos e ao solo. Por isso, a importância da adequada gestão desse resíduo, que pode ter como destino adequado a fertilização dos solos, visto que é rico em cálcio, nitrogênio e potássio (SCHNEIDER et al., 2012).

Para amenizar esses efeitos negativos, deve-se: realizar o devido tratamento e o reuso de água no processo; utilizar o melaço na agricultura, pois aumenta a vida microbiana, o que faz com que as plantas absorvam mais nutrientes, funcionando também como forma de controlar biologicamente possíveis pragas e como alimento para bactérias saudáveis; utilizar a torta de filtro na agricultura, visto que é rica em fósforo, cálcio e possui consideráveis quantidades de micronutrientes, além de sua umidade garantir a brotação da cana-de-açúcar em plantios feitos em épocas de inverno na região Centro-Sul; seguir as normas e utilizar equipamentos de proteção individual; e utilizar equipamentos e empregar métodos que minimizem os efeitos sonoros.

Outra atividade impactante na agroindústria é a produção de etanol. Por meio dessa atividade, impactos negativos são gerados, a saber: produção de efluentes, advindos da limpeza do sistema de produção de açúcar e vinhaça, e que possuem alto potencial de contaminação do solo e da água, além da poluição sonora (Quadro 6). Ao abordarem os tratamentos de efluentes industriais, Araújo et al. (2016) destacam a importância dos processos oxidativos avançados, bem como a importância da reutilização das águas no processo.

Wissmann e Shikida (2017) defendem que a produção da cana-de-açúcar para etanol permitirá o emprego de energias limpas, com o aproveitamento de créditos de carbono; aumento na ocupação permanente de mão de obra local; geração de renda ao longo do ano; indução tecnológica na produção e colheita da cana-de-açúcar; qualificação dos trabalhadores do setor frente sua tecnificação, gerando investimentos em educação e treinamento; e investimentos em complexos agroindustriais de logística, transporte, energia e suporte técnico. 
Outro resíduo comum a essa atividade é a geração de vinhaça. Segundo Paulino et al. (2011), a produção de vinhaça é em média de 13 litros para cada 1 litro de álcool produzido. Diante desse alto potencial gerador, a vinhaça se torna um dos subprodutos que mais causa impactos ao meio ambiente.

Quadro 6 - Listagem descritiva de aspectos, impactos ambientais e suas devidas classificações na atividade de produção do etanol.

\begin{tabular}{|c|c|c|c|c|c|c|c|c|c|c|}
\hline & & TIVIL & DE I & ИPA & TAN & TE: produção do etanol & & & & \\
\hline ASPECTO AMBIENTA & proces & s de & arific & ação & $\begin{array}{l}\text { em c } \\
\text { ho f }\end{array}$ & $\begin{array}{l}\text { ecantadores, fermentação } \\
\text { rmentado }\end{array}$ & $r 1$ & dur & de & \\
\hline & 임 & 岁 & 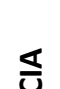 & o & & & & $\begin{aligned} \text { EXE } \\
\text { RESPC }\end{aligned}$ & $\begin{array}{l}\text { JTOR } \\
\text { ISÁV }\end{array}$ & \\
\hline AMBIENTAL & 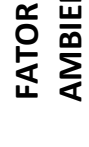 & 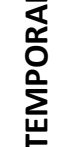 & 冚 & 点 & 일 & MEDIDA AMBIENTAL & AA & SE & OP & SG \\
\hline $\begin{array}{l}\text { 1. Maior geração de } \\
\text { efluentes, advindos } \\
\text { da limpeza do sistema } \\
\text { de produção de } \\
\text { açúcar. }\end{array}$ & físico & AT & $\mathrm{D}$ & $\mathrm{N}$ & - & $\begin{array}{l}\text { - Realizar o devido } \\
\text { tratamento e o reuso de } \\
\text { água no processo. }\end{array}$ & $\mathrm{x}$ & & & \\
\hline $\begin{array}{l}\text { 2. Aumento da } \\
\text { vinhaça, que possui } \\
\text { alto potencial de } \\
\text { contaminação do solo } \\
\text { e da água. }\end{array}$ & físico & AT & $\mathrm{D}$ & $\mathrm{N}$ & - & $\begin{array}{l}\text { - Utilizar vinhaça, pois } \\
\text { possui alto poder } \\
\text { poluente e alto valor } \\
\text { fertilizante; } \\
\text { quantidades adequadas, } \\
\text { pode ser empregada na } \\
\text { agricultura. }\end{array}$ & $\mathrm{x}$ & & $\mathrm{x}$ & \\
\hline 3. Poluição sonora. & físico & AT & $\mathrm{D}$ & $\mathrm{N}$ & - & $\begin{array}{l}\text { - Seguir as normas e } \\
\text { utilizar equipamentos de } \\
\text { proteção individual; } \\
\text { - Utilizar equipamentos e } \\
\text { empregar métodos que } \\
\text { minimizem os efeitos } \\
\text { sonoros. }\end{array}$ & $\mathrm{x}$ & & $\mathrm{x}$ & \\
\hline
\end{tabular}

Obs.: A: adversa; B: benéfica; AT: atual; PA: passado; FU: futuro; D: direta; I: indireta; N: normal; AN: anormal; E: emergencial; (+): positivo; (-): negativo; AA: agroindústria; SE: setor empresarial; OP: órgãos de pesquisa; SG: setor governamental.

Fonte: Elaborado pelos autores (2021).

Estudando a toxicidade e os impactos ambientais relacionados à vinhaça, Lima et al. (2016) revelam que esse subproduto apresenta elevadas concentrações de materiais orgânicos e inorgânicos. E mais, devido ao seu potencial corrosivo, pH baixo (ácido) e elevadas Demanda Bioquímica de Oxigênio (DBO) e Demanda Química de Oxigênio (DQO), esse efluente consiste em um grande causador de danos à fauna e à flora, bem como ao solo e aos lençóis freáticos. Esses mesmos autores ainda descrevem que esse efluente pode ser utilizado como fertirrigação na 
própria cultura de cana-de-açúcar, porém apresenta limitação quanto à dosagem máxima a ser utilizada, pois, se exagerada, pode causar sérios danos ambientais.

Para mitigar os impactos negativos dessa atividade, deve-se: realizar o devido tratamento e o reuso de água no processo; utilizar vinhaça, pois possui alto poder poluente e alto valor fertilizante e, em quantidades adequadas, pode ser empregada na agricultura; seguir as normas e utilizar equipamentos de proteção individual; utilizar equipamentos e empregar métodos que minimizem os efeitos sonoros. Por fim, tem-se a alimentação energética da agroindústria. Essa atividade pode causar os impactos negativos, como o consumo excessivo da biomassa de madeiras, para alimentação da caldeira, e liberação de fuligens e cinzas (Quadro 7).

Quadro 7 - Listagem descritiva de aspectos, impactos ambientais e suas devidas classificações na atividade de alimentação energética da indústria.

\begin{tabular}{|c|c|c|c|c|c|c|c|c|c|}
\hline \multicolumn{7}{|c|}{ ATIVIDADE IMPACTANTE: alimentação energética da agroindústria } \\
\hline \multicolumn{7}{|c|}{ IMPACTO } \\
AMBIENTAL
\end{tabular}

Obs.: A: adversa; B: benéfica; AT: atual; PA: passado; FU: futuro; D: direta; I: indireta; N: normal; AN: anormal; E: emergencial; (+): positivo; (-): negativo; AA: agroindústria; SE: setor empresarial; OP: órgãos de pesquisa; SG: setor governamental.

Fonte: Elaborado pelos autores (2021).

Ao avaliar as emissões atmosféricas provindas do consumo de madeira, como recurso energético no Paraná, Pelanda (2016) pontua que as principais fontes fixas que utilizam o biocombustível madeira no estado são: combustão de lenha em caldeira, secador de grãos, combustão de biomassa diversa em caldeira, combustão de cavaco em caldeira, combustão de derivados de madeira em forno e fornalhas, e combustão de resíduos de madeira em caldeira. 
Essas atividades demandam consumo de biomassa. A autora ainda estima, com base em estudos, que as maiores concentrações expelidas, dentre os poluentes estudados, foram as de monóxido de carbono (CO) e as de material particulado; por sua vez, as menores concentrações estimadas expelidas, dentre os poluentes estimados, foram as de óxido de nitrogênio (NOx) e as de óxido de enxofre (SOx).

Tendo em vista o potencial impactante dessa atividade e a necessidade de amenização dos efeitos desses impactos, deve-se: utilizar madeiras de reflorestamento, como pinus e eucalipto; tentar utilizar outras metodologias energéticas com menor impacto ambiental; utilizar máquinas e equipamentos (ex., filtro de fuligens) que minimizem/ extingue fuligens e cinzas; e utilizar fuligens e cinzas na agricultura ou na construção civil. Importa mencionar que Bacchi e Caldarelli (2015), mesmo constatando evidências de que a expansão da indústria canavieira gerou efeitos positivos sobre o emprego e a renda, não observaram impactos positivos expressivos sobre a saúde e a educação.

Em suma, pode-se afirmar que os principais resultados positivos das agroindústrias canavieiras nas regiões onde estão inseridas são a geração de emprego, a redução gradativa da mão de obra temporária e a geração de renda e de impostos. Além disso, permite que o Brasil utilize fontes energéticas renováveis, como o etanol, contribuindo para o bem-estar daqueles que fazem uso desse sistema (SHIKIDA \& SOUZA, 2009; CARVALHO et al., 2013a, b).

Carvalho e Marin (2011) também observaram essas mesmas vantagens e desvantagens elencadas nas regiões produtoras de cana-de-açúcar, e apontaram, ainda, um problema que tem passado despercebido e que está relacionado com a agricultura familiar: a migração de trabalhadores para a agroindústria canavieira diminuiu a mão-de-obra para esse tipo de unidade produtora, sendo necessária a redução das áreas ocupadas com determinadas culturas, em geral, alimentares, mais exigentes em mão de obra. Assim, há a possibilidade de que a migração e a expansão da cana-de-açúcar conduzam à redução da produção de alimentos, que pode ser agravada pela tendência de aumento das importações de alimentos no país (CARVALHO, 2007; LOURENZANI \& CALDAS, 2014).

Importa destacar que ainda existe controvérsia sobre o conflito entre os biocombustíveis (etanol) e a produção de alimentos. Esse é um assunto complexo e que envolve inúmeras variáveis, de tal modo que é preciso entender o tamanho dos impactos das mudanças provenientes das condições do mercado, dos estímulos da política agrícola e dos impactos de eventos climáticos na cultura. Somente assim é possível confrontar o crescimento da produção 
dos alimentos com a evolução da demanda interna, bem como analisar as eventuais necessidades de importações e o comportamento de seus preços (AGUIAR \& SOUZA, 2014).

A substituição de culturas alimentares gera pressão nos preços e possível escassez de alimentos, elevação do preço da terra, aspectos institucionais e marginalização de comunidades locais e agricultores familiares (SAUER \& LEITE, 2012; GAMBORG, PALMER, SANDOE, 2012; GILIO, 2015). Fonseca et al. (2015) revelaram que a crescente participação da cultura da cana-de-açúcar se deu basicamente pela incorporação de novas áreas cultiváveis e pela substituição de áreas ocupadas com diversas culturas agrícolas, o que tem acontecido predominantemente em regiões menos desenvolvidas, como no Norte de Goiás, onde os impasses sociais, graças à agroindústria canavieira, têm se intensificado.

O impacto social da atividade canavieira pode ser ainda mais exacerbado. Neste sentido, questiona-se se o aumento da produção de biocombustíveis, derivados da cana-de-açúcar, afeta o suprimento global de alimentos, pondo em risco a sustentabilidade da produção agrícola. Isso porque países em desenvolvimento, em algum momento, deparar-se-ão com o seguinte dilema: produzir alimentos para consumo ou investir na geração de energia. A propensão à escolha depende exclusivamente de questões econômicas (PONTI \& GUTIERREZ, 2009; WISSMANN \& SHIKIDA, 2017).

A expansão da cana-de-açúcar justifica-se pela viabilidade econômica, ficando em plano secundário o planejamento para equacionar os impactos sociais e ambientais dessa atividade agrícola, que é pautada no latifúndio e na utilização da força de trabalho. Dessa forma, um dos principais desdobramentos da expansão do setor sucroalcooleiro é a concentração de renda e de terra, pois contribuiu para acentuar as desigualdades socioeconômicas existentes no campo (SEGATTI, 2009; CUNHA \& PREVITALI, 2012; LELIS \& HESPANHOL, 2013).

Com isso, a expansão da agroindústria da cana-de-açúcar provoca problemas relacionados a fatores que afetam a segurança e a saúde dos trabalhadores, quais sejam: fisiológicos, relacionados à organização, à saúde, às condições de trabalho e a aspectos sociais decorrentes da migração e de alojamentos precários (CANÇADO, 2003; SANTOS \& BATISTA, 2018). Dentre os impactos sociais, destacam-se o da sazonalidade da mão-de-obra e o da rotação de culturas, envolvendo a inflação dos serviços urbanos que recebem essa mão-de-obra (MONTEIRO, ELABRAS-VEIGA, COUTINHO, 2010).

Assim, percebe-se a necessidade de promover políticas de gestão da terra, com o fim de reconciliar e propiciar a promoção de sinergias entre diferentes usos do solo, bem como para alimentos e biocombustíveis (MOHR \& RAMAN, 2013). O setor produtivo das sociedades 
organizadas tem sido surpreendido pela intensidade das pressões regulatórias em suas operações, em especial as que se referem a um comportamento socioambiental responsável, cada vez mais considerado fundamental para a sustentabilidade do crescimento econômico e o bem-estar da humanidade (LIBONI \& CEZARINO, 2012). Importa salientar que tanto a comunidade científica quanto a sociedade civil têm se preocupado com as questões ambientais e com a preservação da vida no planeta, levando muitos produtores a adequarem a atividade agrícola a uma ação que seja ambientalmente correta e economicamente viável (FERREIRA, 2013; FERREIRA et al. 2017).

Silva, Oliveira e Lima (2010) observaram que a expansão da cana-de-açúcar, quando realizada de maneira mais sustentável (utilizando racionalmente os resíduos gerados pela agroindústria) e com uso de novas tecnologias, com foco na melhoria do rendimento e da produção da cultura, pode não impactar significativamente a produção de alimentos, uma vez que os ganhos de produtividade contribuem para contrabalançar a ocupação de novas áreas pela cana-de-açúcar. Entretanto, a utilização de resíduos líquidos da indústria sucroalcooleira, como fertilizantes para a obtenção de maiores rendimentos da cultura, pode aumentar o risco da degradação ambiental, devido ao elevado potencial poluidor - quantitativo e qualitativo - desses resíduos (ROSSETTO, 2004; DEUS \& BAKONYI, 2012).

A expansão do setor sucroalcooleiro no Norte de Goiás tem causado intensa reestruturação espacial, produtiva e econômica. Essa reestruturação tem proporcionado alterações significativas na dinâmica econômica, social e ambiental. Com isso, apesar das vantagens geradas pela expansão da cana-de-açúcar, as desvantagens são maiores. Logo, é necessário ter precaução com a expansão dessa cultura, tendo em vista que futuramente seus impactos poderão se tornar ainda mais prejudiciais (LELIS \& AVELINO JÚNIOR, 2015).

\section{Considerações Finais}

Na região Norte de Goiás, no que concerne aos impactos negativos do transporte a ao processamento da cana-de-açúcar, destacam-se aqueles relacionados poluição do ar, solo e água, impactos na fauna e flora, bem como na saúde dos trabalhadores da agroindústria. Salienta-se, porém, que a expansão da agroindústria canavieira na região Norte aumentou a oferta de vagas de emprego, com elevação da renda dos trabalhadores. Todavia, com relação às condições de trabalho e à saúde, esse setor ainda tem apresentado avanços pouco significativos. 
Somam-se a isso a expropriação e a migração dos produtores familiares, devido ao avanço da cultura da cana-de-açúcar.

De maneira geral, pode-se afirmar que os impactos socioeconômicos e ambientais provocados pelo transporte até o processamento da cana-de-açúcar na região Norte de Goiás podem ser considerados de média ou alta relevância, pelo fato de a indústria localizada nessa região ainda apresentar baixos investimentos para a mitigar os impactos negativos da atividade.

\section{Referências}

AGUIAR, C. J.; SOUZA, P. M. Impactos do crescimento da produção de cana-de-açúcar na agricultura dos oito maiores estados produtores. Revista Ceres, Viçosa, v. 61, n. 4, p. 482-493, ago. 2014.

ALVARENGA, R. P.; QUEIROZ, T. R. Caracterização dos aspectos e impactos econômicos, sociais e ambientais do setor sucroalcooleiro paulista. In: XLVI Congresso da Sociedade Brasileira de Economia, Administração e Sociologia Rural, p.21, 2008. Anais [...]. Disponível em: https://ageconsearch.umn.edu/record/113960/files/691.pdf. Acesso em: 22 jul. 2020.

ARAÚJO, K. S. et al. Processos oxidativos avançados: uma revisão de fundamentos e aplicações no tratamento de águas residuais urbanas e efluentes industriais. Revista Ambiente \& Água, Taubaté, v. 11, n. 2, p. 337-401, abr./jun. 2016.

ASSOCIAÇÃO BRASILEIRA DE NORMAS TÉCNICAS - ABNT. NBR ISO 14001:2015. Sistemas de Gestão Ambiental: requisitos com orientações para uso. 2015. Disponível em: https://www.abntcatalogo.com.br/norma.aspx?ID=345116. Acesso em: 25 jan. 2021.

BACCHI, M. R. P; CALDARELLI, C. Impactos socioeconômicos da expansão do setor sucroenergético no Estado de São Paulo entre 2005 e 2009. Nova Economia, Belo Horizonte, 2015.

BARBIERI, J. C. Gestão Ambiental Empresarial: conceitos, modelos e instrumentos. 2. ed. São Paulo: Saraiva, 2007.

BRASIL. Conselho Nacional do Meio Ambiente. Resolução CONAMA n.o 01, de 23 de janeiro de 1986. Dispõe sobre critérios básicos e diretrizes gerais para a avaliação de impacto ambiental. Brasília: 17 fev. 1986. Disponível em:

http://www2.mma.gov.br/port/conama/res/res86/res0186.html. Acesso em: 04 abr. 2021.

BRASIL. Conselho Nacional do Meio Ambiente. Resolução CONAMA n.o 306, de 5 de julho de 2002. Estabelece os requisitos mínimos e o termo de referência para realização de auditorias ambientais. Brasília, 19 jul. 2002. Disponível em:

https://www.legisweb.com.br/legislacao/?id=98306. Acesso em: 04 abr. 2021.

CANÇADO, J. E. D. A poluição atmosférica e sua relação com a saúde humana na região canavieira de Piracicaba - SP. Tese (Doutorado em Ciências-Área de Concentração: Patologia da Faculdade de Medicina da Universidade de São Paulo) São Paulo. 2003.

CARVALHO, E. R.; VIAN, C. E. F.; BRAUN, M. B. S. A Inserção da responsabilidade social no setor sucroalcooleiro: motivações e benefícios do comportamento socialmente responsável no setor. Informe Gepec, v. 15, n. 2, p. 155-190, 2011. 
CARVALHO, H. M. Impactos econômicos, sociais e ambientais devido à expansão da oferta do etanol no Brasil. 2007. Disponível em http://www.landaction.org/spip/spip.php?article190. Acesso em: 10 jul. 2020.

CARVALHO, J. M.; ANDREOTTI, M.; BUZETTI, S.; CARVALHO, M. P. Produtividade de cana soca sem queima em função do uso de gesso e vinhaça. Pesquisa Agropecuária Tropical, Goiânia, v. 43, n. 1, p. 1-9, jan./mar. 2013a.

CARVALHO, L. C.; BUENO, R. C. O. F.; CARVALHO, M. M.; FAVORETO, A. L.; GODOY, A. F. Canade-açúcar e álcool combustível: histórico, sustentabilidade e segurança energética.

Enciclopédia Biosfera, Goiânia, v.9, n.16, p.530-543, 2013b.

CARVALHO, S. P.; MARIN, O. B. Agricultura familiar e agroindústria canavieira: impasses sociais. Revista de Economia e Sociologia Rural, Brasília, v.49, n.3, p. 681-707, 2011.

CRUZ, I. S.; ANDRADE, I. C. B.; SOUZA, R. R.; FACCIOLI, G. G. Efluentes da indústria canavieira do estado de Sergipe. Interfaces Científicas - Exatas e Tecnológicas, Aracaju, v.2, n.2, p. 27-36, 2016.

CUNHA, T. R.; PREVITALI, F. S. Os impactos socioambientais: considerações sobre o setor agroindustrial da cultura de cana-de-açúcar no Brasil. 2012. Disponível em: http://www.seer.ufu.br/index.php/horizontecientifico/article/view/18161/14997. Acesso em: 20 jul. 2020.

DEUS, R. M.; BAKONYI, S. M. C. O. impacto da agricultura sobre o meio ambiente. Revista Eletrônica em Gestão, Educação e Tecnologia Ambiental, v.7, n. 7, p. 1306-1315, 2012.

DIAS, L. F. R.; MACÊDO, R. M.; PELLI, A. Pressão sonora, poluição e a saúde das pessoas. Acta Biologica Brasiliensia, v. 1, n. 1, p. 51-65, 2018.

FERREIRA, L. C. G.; ARAÚJO SOBRINHO, F. L. A dinâmica canavieira na microrregião Ceres, Goiás: das colônias agrícolas nacionais ao agronegócio sucroenergético. Caderno Prudentino de Geografia, Presidente Prudente, v. 1, n. 39, p. 146-175, jan./jun. 2017.

FERREIRA, M. C. Gestão ambiental: um estudo em empresas do setor sucroalcooleiro em Goiás. Revista Pensamento Contemporâneo em Administração - RPCA, Rio de Janeiro, v. 7, n. 3, jul./set., p. 59-80, 2013.

FONSÊCA, M. V. R.; LOURENZANI, W. L.; BERNARDO, R.; LOURENZANI, A. E. B. S. Expansão da cana-de-açúcar e as mudanças no uso da terra no Escritório de Desenvolvimento Rural (EDR) de Tupã-SP. Espacios. v. 36, n.1, p.5-11, 2015.

FRAVET, P. R. F. et al. Efeito de doses de torta de filtro e modo de aplicação sobre a produtividade e qualidade tecnológica da soqueira de cana-de-açúcar. Ciência e Agrotecnologia, Lavras, v. 34, n. 3, p. 618-624, maio/jun. 2010.

GAMBORG, C.; PALMER, C.; SAND ØE, P. Ethics of wildlife management and conservation: what should we try to protect? Nat. Educ. Knowl., v. 3, n.10, 8p., 2012.

GILIO, L. Análise dos impactos socioeconômicos da expansão do setor sucroenergético. Dissertação (Mestrado). Universidade de São Paulo Escola Superior de Agricultura "Luiz de Queiroz", Piracicaba, 2015.86 p.

INSTITUTO BRASILEIRO DE GEOGRAFIA E ESTATÍSTICA - IBGE. Produção agrícola municipal. 2019. Disponível em: https://www.ibge.gov.br/estatisticas/economicas/agricultura-epecuaria/9117-producao-agricola-municipal-culturas-temporarias-epermanentes.html?=\&t=resultados. Acesso em: 12 abr. 2021. 
LELIS, L. R. M.; AVELINO JÚNIOR, F. J. Os impactos gerados pela expansão da cana-de-açúcar na microrregião de Dracena - SP. Geografia em Questão, v. 8, n.1, p. 124-137, 2015.

LELIS, L. R. M.; HESPANHOL, R. A. de M. Dinâmica agropecuária do município de Dracena-SP: da cafeicultura à cana-de-açúcar. Geografia em Questão, v. 6, n. 2, p. 181-198, 2013.

LEONARDO, A. S.; OLIVEIRA, C. G. S.; MARQUES, L. M.; SILVA, L. M. S. Usina de álcool: impactos ambientais negativos e medidas para produção mais limpa. Colloquium Exactarum, v. 4, n. Especial, jul./dez., p.149-156, 2012.

LIBONI, L. B.; CEZARINO, L. O. Impactos sociais e ambientais da indústria da cana-de-açúcar. Future Studies Research Journal, São Paulo, v. 4, n. 1, p. 202-230, jan./jun. 2012.

LIMA, F. de A. et al. Revisão sobre a toxicidade e impactos ambientais relacionados à vinhaça, efluente da indústria sucroalcooleira. Cadernos UniFOA, v. 11, n. 32, p. 27-34, 2016.

LOURENZANI, W. L.; CALDAS, M. M. Mudanças no uso da terra decorrentes da expansão da cultura da cana-de-açúcar na região oeste do estado de São Paulo. Ciência Rural, Santa Maria, v.44, n.11, p.1980-987, nov., 2014.

MARCELINO, R. B. P. et al. Tendências e desafios na aplicação de tecnologias avançadas para o tratamento de efluentes industriais não biodegradáveis. Revista da Universidade Federal de Minas Gerais, Belo Horizonte, v. 20, n. 2, p. 358-383, 2013.

METCALF, L.; EDDY, H. P. Tratamento de efluentes e recuperação de recursos. 5. ed. Porto Alegre: AMGH, 2016.

MIRANDA, P. E. V. Materiais particulados: produtos ameaçadores resultantes da queima de combustíveis. Revista Matéria, v. 18, n. 4, out./dez. 2013.

MOHR, A.; RAMAN, S. Lessons from first generation biofuels and implications for the sustainability appraisal of second generation biofuels. Energy Policy, Chattanooga, v. 63, p. 114-122, Dec., 2013.

MONTEIRO, J. M. G.; ELABRAS-VEIGA, L. B.; COUTINHO, H. L. da C. Projeto SENSOR: políticas públicas relacionadas à expansão da cana-de-açúcar para a produção de biocombustíveis. Rio de Janeiro: Embrapa Solos, 2010.

NOGUEIRA, M. A. F. S.; GARCIA, M. S. Gestão dos resíduos do setor industrial sucroenergético: estudo de caso de uma usina no município de Rio Brilhante, Mato Grosso do Sul. Revista Eletrônica em Gestão, Educação e Tecnologia Ambiental - REGET, v. 17 n. 17 p. 3275-3283, dez., 2013.

PACHECO, G.; SILVA, F. F. Utilização de resíduos gerados por indústria do setor sucroalcoleiro, pela RAUDI Indústria e Comércio LTDA, na produção de bicarbonato de sódio. Agro@mbiente On-line. v. 2, n. 1, jan./jun., Boa Vista, 2008.

PAIVA, F. F. G.; MARIA, V. P. K. Gestão ambiental de resíduos industriais: análise de gestão e reaproveitamento de resíduos da indústria sucroalcooleira. Revista Brasileira de Gestão Ambiental e Sustentabilidade, v.5, n. 9, p. 157-166, 2018.

PAULINO, J. et al. Estudo exploratório do uso da vinhaça ao longo do tempo. II. Características da cana-de-açúcar. Revista Brasileira de Engenharia Agrícola e Ambiental, v. 15, n. 3, p. 244249, mar. 2011.

PASSOS, H. S. Impactos da expansão da cana-de-açúcar: percepção e prática científica. Tese (Doutorado). Universidade Federal de Goiás - UFG, 2015. 207p. 
PELANDA, K. A. Emissões atmosféricas provenientes do consumo de madeira como biocombustível no Paraná. 2016. Dissertação (Mestrado em Engenharia Florestal) Universidade Federal do Paraná, Curitiba, 2016. 84p.

PIACENTE, F.J. Agroindústria Canavieira e o Sistema de Gestão Ambiental: o caso das usinas localizadas nas Bacias Hidrográficas dos rios Piracicaba, Capivari e Jundiaí. Dissertação (Mestrado em Desenvolvimento Econômico) - UNICAMP, Campinas. 2005. 181p. Disponível em: <http://libdigi.unicamp.br/document/?code=vtls000386200>. Acesso em: 22/07/2020.

PONTI, L.; GUTIERREZ, A. P. Overview on biofuels from a European perspective. Bulletin of Science Technology and Society, Roma, p. 493-504, 2009.

QUEIROZ, A. M. Considerações sobre a expansão da cultura da Cana-de-açúcar em Goiás entre 2000 e 2010. Conjuntura Econômica Goiana, Goiânia, p. 39-50, set. 2012.

REZENDE, L. M.; MAGALHÃES, P. A. N. R. Impactos sociais e ambientais da indústria sucroalcooleira no estado de Goiás. Universidade de Rio Verde - UniRV. Disponível em: http://www.unirv.edu.br/conteudos/fckfiles/files/impactos \%20sociais\%20e\%20ambientais\%20da\%20industria\%20sucroalcooleira\%20no\%20estado\%20de \%20goias.pdf. Acesso em: 22/07/2020.

RIBEIRO, H. Sugar cane burning in Brazil: respiratory health effects. Revista de Saúde Pública, v. 2, n. 42, p. 370-376, fev. 2008.

RIBEIRO, N. V.; FERREIRA, L. G.; FERREIRA, N. C. Expansão sucroalcooleira no estado de Goiás: uma análise exploratória a partir de dados sócio-econômicos e cartográficos. Geografia, Rio Claro, v. 35, p. 331-344, 2010.

RODRIGUES, L. D. A cana-de-açúcar como matéria-prima para a produção de biocombustíveis: impactos ambientais e o zoneamento agroecológico como ferramenta para mitigação.

Trabalho de Conclusão de Curso, Faculdade de Engenharia, Universidade Federal de Juiz de Fora, Juiz de Fora, p.20, 2010.

ROSSETTO, R. A cultura da cana, da degradação à conservação. Visão Agrícola, n. 1, p. 80-85, jan./jun. 2004.

SANCHEZ, L. E. Avaliação de impacto ambiental: conceito e métodos. 3. ed. São Paulo: Oficina de Textos, 2020.

SANTOS, T. M.; BATISTA, R. O. S. Agrotóxicos, uma violência silenciosa: a saúde dos cortadores da cana-de-açúcar em Laranjeiras/Sergipe. Campo-Território: revista de geografia agrária, v. 13, n. 29, p. 189-208, abr., 2018.

SAUER, S.; LEITE, S. P. Expansão agrícola, preços e apropriação de terra por estrangeiros no Brasil. Revista de Economia e Sociologia Rural, v. 50, n. 3, p. 503-524, 2012.

SCHNEIDER, C. F. et al. Formas de gestão e aplicação de resíduos da cana-de-açúcar visando redução de impactos ambientais. Revista Verde de Agroecologia e Desenvolvimento Sustentável, v. 7, n. 5, p. 8-17, 2012.

SEGATTI, S. A expansão da agroindústria sucroalcooleira e a questão do desenvolvimento da Microrregião de Dracena - SP. Dissertação (Mestrado em Geografia) - Faculdade de Ciências e Tecnologia, Universidade Estadual Paulista, Presidente Prudente, São Paulo, 2009. 153 p.

SHIKIDA, P. F. A.; SOUZA, E. C. Agroindústria canavieira e crescimento econômico local. Revista de Economia e Sociologia Rural, Piracicaba, v. 47, n. 3, p. 569-600, jul./set., 2009. 
SILVA, A.; OLIVEIRA, D.E.; LIMA, D. Segurança Alimentar: estudo sobre a produção de alimentos em Goiás, 1990-2009. In: 5o. Encontro Nacional da ANPPAS, Florianópolis. Anais [...], ANPPAS. p.1-20, 2010.

SILVA, A. L. M. Direito do meio ambiente e dos recursos naturais. São Paulo: Revista dos Tribunais, 2004. v. 1.

SILVA FILHO, L. A.; SILVA, J. L. M.; LIMA, M. M. F. Mecanização agropecuária e o mercado de trabalho formal no cultivo da cana-de-açúcar no Nordeste - 2000/2010. Revista Geonordeste, São Cristóvão, ano 25, n. 1, p. 116-139, jan./jul. 2014.

SILVA, F. C.; SHIBAO, F. Y.; SANTOS, M. R. Identificação e classificação de aspectos e potenciais impactos ambientais em uma indústria do segmento de plásticos. Revista Eletrônica Gestão e Serviços, v. 6, n. 1, p. 1084-1099, 2015.

SOUZA, J. K. C.; MESQUITA, F. O.; DANTAS NETO, J.; SOUZA, M. M. A.; FARIAS, C. H. A.; MENDES, H. C.; NUNES, R. M. A. Fertirrigação com vinhaça na produção de cana-de-açúcar. Agropecuária Científica no Semiárido - ACSA, v. 11, n. 2, p. 7-12, abr./jun., 2015.

WISSMANN, M. A.; SHIKIDA, P. F. A. Impactos econômicos, ambientais e sociais da agroindústria canavieira no Brasil. Revista Desenvolvimento, Fronteiras e Cidadania, v.1, n.1, p. 134-160, jul. 2017. 